Hills 20 or more years ago; in addition I now have records of over 30 recent sightings in this area.

In parts of the Maritimes the cougar was thought to be extinct since before the turn of the century, but it has been recently shown that a small breeding group still exists in that region. I think that it is possible that a similar condition exists in Saskatchewan. Cougars have probably always been comparatively rare in the province. This large cat is mainly. nocturnal, shy, wary, and lives in different habitats. However, two essential conditions for cougar range are a plentiful supply of deer and a sparse human population. Their main food is deer, although they also eat small mammals. Occasionally they will kill cattle or foals when left unguarded, but in eastern Canada there is little evidence of this occurring and it would appear that when deer are plentiful cougars seldom attack domestic stock.

The considerable information on which this brief account of my study is based has been obtained over a relatively short period of time and it appears that further records may be forthcoming. I intend to prepare a full account of our findings at a later date and presently am hoping to elicit more information. The writer wculd welcome any further evidence or sightings either past or present. It would particularly be appreciated if anyone with new information or recent sightings would contact me as soon as possible after the event so that as much evidence as possible may be gathered. This is the only way in which it will be possible to determine whether or not there is a resident population of the cougar in Saskatchewan. Correspondents should contact me directly at 1919 Scarth Street, Regina.

ED. NOTE: Bruce Wright's book - The Ghost of North America (1959. Vanguard Prejs, New York. 133 pp.) - shculd be read by everyone interested in conserving wildlife species. Wright's "Ghost" is the mountain lion or cougar, a relatively rare animal which ought to receive protection, at least as a game animal. We agree with Wright when he says: "DON'T SHOOT TO PROVE THERE IS ONE..."

\section{ATTENTION ROCKHOUNDS}

\section{by Watson Crossley, Grandview, Manitoba}

Since the last issue of the Blue Jay with its item on rock tumblers and a news note from the Saskatoon lapidary and mineral club seven letters have come in encouraging us to continue with a rockhound section. Tom Bird suggests, however, that less scientific items be put in a newsletter and this may be a good idea. Since there is not enough space for items on our hobby in this issue, I will send out a mimeographed newsletter to all those requesting it.

In this letter I shall attempt to answer two of the questions most commonly asked me. First, what sort of equipment should one get for the cutting and polishing of rocks, and second, can one make some or all of the machine oneself?

If a person is really interested in making a start in cutting rocks I would certainly recommend that he subscribe to one of the lapidary magazines. Then a study of various kinds of equipment advertised can be made. The person should also visit someone who has equipment and actually see the things that will be required by this hobby.

Generally I would recommend the purchase, rather than the making, of equipment, especially the saw, for this is a precision machine. Lap and polishing machines are not so difficult to make, however, and they may be made at home.

\section{NOTICE TO SASKATCHEWAN ARCHAEOLOGISTS}

A meeting of all interested people will be held in the Saskatchewan Museum of Natural History, Regina, on April 20, 1963, to form a Saskatchewan Archaeological Society. This will be an all-day meeting, and officers will be elected at that time.

The interim committee planning the meeting has already distributed a newsletter (February, 1963). If you are interested in receiving this letter, or in details of the programme for the April meeting, write Bruce McCorquodale at the Museum. 